\title{
THỰC TRANG ĐI LÀM THÊM CỦA SINH VIÊN TRƯỜNG ĐẠI HỌC KỸ THUẬT Y TẾ HẢI DƯƠNG NĂM 2019
}

\author{
Lê Thúy Hường*, Hoàng Thị Thu Hiền* \\ Nguyễn Dương Cầm*, Phạm Thị Thanh Thủy* \\ entertainment areas: $12 \%$; The number of working \\ hours: less than 4 hours/day: $50.4 \%$; 4 to 6 \\ hours/day: $35.6 \%$; 6-8 hours/day: $10.1 \%$; Average \\ income/working day <100,000 VND: $50.6 \%$; > \\ 300000 VND/day: 2\%; Affect the academic \\ performance of the students and learning results from \\ part-time employment: $56.9 \%$; Desire to receive \\ advice and support when working part-time: $94.3 \%$
}

TÓM TẮT

Mục tiêu: Mô tả thực trang đi làm thêm của sinh viên Trường Đai học Kỹ̃ thuâtt $Y$ tế Hải Dương năm 2019 và đề xuất giải pháp tằng cường quản lý sinh viên đi làm thêm. Phương pháp: nghiên cứu mô tả ngang qua khảo sát lấy ý kiến 1433 sinh Trường ĐH Kỹ thuật Y tế Hải Dương năm 2019. Kết quả: Tỷ lệ sinh viền đi làm thêm: $41.4 \%$; Lý do chủ yếu khiến sinh viên đi làm thêm: thu nhâp: $42.2 \%$; khẳng định bản thân: $42.2 \%$; Tận dụng thời gian rảnh rỗi; $6.1 \%$; Rèn luyên kỹ năng làm việc; tích lũy kinh nghiêm cho nghề nghiệp hoặc tìm cớ hội việc làm sau khi tốt nghiệp: $1 \%-3,9 \%$. Tính chất công việc làm thêm: Làm việc phù hợp với chuyên ngành được đào tạo: $18.9 \%$; gia sư: $10.8 \%$; tiếp thi sản phẩm cho các doanh nghiệp và phát tờ rơi: $21.1 \%$; Bán hàng online: $22.9 \%$; lao động thủ công đơn thuân: $14.2 \%$; phục vu nhà hàng ăn uống và khu vui chơi giải trí:12\%; Thời gian làm thêm: dưới 4 giờ/ngày: $50.4 \%$; 4 đến 6 giờ/ngày: 35.6\%; 6-8 giờ/ngày 10.1\%; Anh hưởng tới quá trình học tập và kết quả học tâp từ đi làm thêm: 56.9\%; Mong muốn nhận được sự tư vấn, hỗ trợ khi đi làm thêm: $94.3 \%$

Từ khóa: Sinh viên, đi làm thêm, Đại học Kỹ thuật Y tế Hải Dương

\section{SUMMARY}

THE CURRENT SITUATION OF STUDENTS' PART-TIME EMPLOYMENT AT HAI DUONG MEDICAL TECHNICAL UNIVERSITY IN 2019

Objectives: Describe the current situation of students' part-time employment at Hai Duong Medical Technical University in 2019 and propose solutions to strengthen the management of students working parttime. Methods: a descriptive cross-sectional survey of 1433 students at Hai Duong Medical Technical University in 2019. Results: Percentage of students working part-time: $41.4 \%$; For reasons of taking parttime employment: income: $42.2 \%$; self-affirmation: $42.2 \%$; taking advantage of free time: $6.1 \%$; practicing the working skill, improving the experience for a career or finding a job opportunities postgraduation: $1 \%-3,9 \%$. Kinds of part-time employment: Working relevant with the training major: $18.9 \%$; tutor: $10.8 \%$; marketing and trading products for businesses and leaflets: $21.1 \%$; Online sales: $22.9 \%$; manual labor: 14.2\%; serving in restaurants and

*Trường Đại học Kỹ thuật Y tế Hải Dương

Chịu trách nhiệm chính: Lê Thúy Hường

Email: thuyhuongdhy@gmai.com

Ngày nhận bài: 12.4.2021

Ngày phản biện khoa học: 24.5.2021

Ngày duyệt bài: 14.6.2021

\section{I. ĐẶT VẤN ĐỀ}

Tại các Trường đại học, công tác quản lý sinh viên giữ vai trò đặc biệt quan trọng bởi quản lý SV tốt sẽ tạo điều kiện và môi trường thuận lợi cho việc trang bị kiến thức, kỹ năng chuyên môn cũng như rèn luyện phẩm chất đạo đức, nhân cách, tác phong, lối sống cho người học.

Trường Đại học Kỹ thuật $Y$ tế Hải Dương hiện đang đào tạo bác sĩ đa khoa, Điều dưỡng và Kỹ thuật $Y$ học ở trình độ đại học. Công tác quản lý sinh viên giữ vai trò đặc biệt quan trọng trong quá trình đảm bảo công tác giáo dục toàn diện cho người học của nhà trường. Hiện tại, sinh viên của Trường đến từ các tỉnh thành trong cả nước, đào tạo theo học chế tín chỉ sinh viên hoàn toàn có thể chủ động trong việc sắp xếp thời khóa biểu của mình một cách hợp lí, thậm chí một số sinh viên có thể vừa học tập vừa đi làm thêm. Đi làm thêm đem lại một số tác động tích cực nếu sinh viên tìm kiếm được công việc làm thêm phù hợp đồng thời biết cách bố trí thời gian học tập và làm việc hiệu quả. Khi đi làm thêm, sinh viên sẽ có thêm thu nhập trang trải cho các nhu cầu sinh hoat cá nhân đồng thời có môi trường thuận lợi để cải thiên kỹ năng giao tiếp, trau dồi kinh nghiệm và kiến thức thực tiễn. Tuy nhiên nếu sinh viên chạy theo thu nhập, lựa chọn công việc không phù hợp, có áp lực lớn sẽ ảnh hưởng đến giờ giấc sinh hoạt, sức khoẻ và kết quả học tập thậm chí bị lôi cuốn vào những công việc có rủi ro cao, dễ bị lợi dụng hoặc sa đà vào các việc làm dẫn tới hành vi vi phạm pháp luật. Do vậy, những thông tin cơ bản về thực trạng làm thêm của sinh viên sẽ cung cấp cơ sở quan trọng để đề xuất giải pháp tăng cường quản lý sinh viên đi làm thêm. Nghiên cứu được thực hiện với mục tiêu: Mô tả thực trạng đi làm thêm của sinh viên Trường Đại học Kỹ thuật Y tế Hải Dương năm 2019 và đề xuât giải pháp tăng cường quản lý sinh viên đi làm thêm. 
II. ĐỐI TƯƠNGG VÀ PHƯƠNG PHÁP NGHIÊN CỨU

1. Thiết kế nghiên cứu: nghiên cứu mô tả ngang qua khảo sát ý kiến 1433 sinh viên Trường ĐH kỹ thuật Y tế Hải Dương năm 2019.

2. Bộ công cự nghiên cứu và kĩ thuật thu thập sổ liệu: 01 bộ phiếu khảo sát tự điền dành cho sinh viên các chuyên ngành của Trường Đại học Kỹ thuật Y tế Hải Dương

III. KẾT QUẢ NGHIÊN CứU

Thực trang đi làm thêm của sinh viên

Bảng 1: Giới tính, năm hoc tai trường và ngành học của đôi tượng nghiên cứu

\begin{tabular}{|c|c|c|c|}
\hline \multicolumn{2}{|c|}{$(\mathbf{n = 1 4 3 3 )}$} & SL & $\mathbf{( \% )}$ \\
\hline \multirow{2}{*}{$\begin{array}{c}\text { Giới } \\
\text { tính }\end{array}$} & Nam & 540 & 37.7 \\
\cline { 2 - 4 } & Nữ & 893 & 62.3 \\
\hline
\end{tabular}

Nhận xét: Tống số đối tượng nghiên cứu là 1433 sinh viên; Nam chiếm 37.7\%; nữ chiếm $62.3 \%$.

\section{Bảng 2: Tỷ lệ sinh viên đỉ làm thêm}

\begin{tabular}{|c|c|c|}
\hline $\mathbf{n = 1 4 3 3}$ & $\mathbf{S L}$ & $\mathbf{\%}$ \\
\hline Sinh viên có tham gia đi làm thêm & 593 & $\mathbf{4 1 . 4}$ \\
\hline Sinh viên không đi làm thêm & 840 & 58.6 \\
\hline
\end{tabular}

Nhận xét: Sinh viên đi làm thêm chiếm tỷ lệ 41.4\% tổng số đối tượng nghiên cứu

Bảng 3: Lý do sinh viên đỉ làm thêm

\begin{tabular}{|c|c|c|}
\hline $\mathbf{n}=\mathbf{5 9 3}$ & $\mathbf{S L}$ & $\mathbf{( \% )}$ \\
\hline Muốn có thu nhập & 250 & $\mathbf{4 2 . 2}$ \\
\hline Muốn tự khẳng định bản thân & 250 & $\mathbf{4 2 . 2}$ \\
\hline $\begin{array}{c}\text { Được trải nghiềm, tích luỹ kiến } \\
\text { thức sống, kiến thức thực tế }\end{array}$ & 97 & 16.4 \\
\hline $\begin{array}{c}\text { Có cơ hôi phát triến bản thân } \\
\text { \& kỹ năng giao tiếp }\end{array}$ & 60 & 10.1 \\
\hline Tận dụng thời gian rảnh rôi & 36 & 6.1 \\
\hline Lý do khác & 150 & 24.9 \\
\hline
\end{tabular}

Nhân xét: Có nhiều lý do khiến sinh viên đi làm thểm. Trong đó lý do chủ yếu là: muốn có thu nhập $(42.2 \%)$ và muốn tự khẳng định bản thân $(42.2 \%)$.

Bảng 4: Tiêu chí lựa chọn công việc làm thêm

\begin{tabular}{|c|c|c|}
\hline $\mathbf{n}=\mathbf{5 9 3}$ & $\mathbf{S L}$ & $\mathbf{( \% )}$ \\
\hline $\begin{array}{c}\text { Thời gian làm việc không trùng với } \\
\text { lịch học tại trường }\end{array}$ & 414 & 69.8 \\
\hline $\begin{array}{c}\text { Công việ̂ làm thềm liên quan đến } \\
\text { chuyển ngành đang theo học }\end{array}$ & 252 & 42.5 \\
\hline $\begin{array}{c}\text { Có cơ hội phát triến kỹ năng giao } \\
\text { tiếp }\end{array}$ & 214 & 36.1 \\
\hline Thu nhập cao & 209 & 35.2 \\
\hline $\begin{array}{c}\text { Có cơ hội trải nghiệm, tích luỹ kiến } \\
\text { thức sống, kiến thức thực tế }\end{array}$ & 156 & 26.3 \\
\hline Khác & 43 & 7.3 \\
\hline
\end{tabular}

Nhân xét: Tiêu chí được sinh viên quan tâm nhất khỉ lựa chọn công viểc làm thêm là: Thời gian làm việc không trùng với lịch học tại trường: $69.8 \%$;
Bảng 5: Tính chất công việc làm thêm

\begin{tabular}{|c|c|c|}
\hline $\mathbf{n}=\mathbf{5 9 3}$ & $\mathbf{S L}$ & $\mathbf{( \% )}$ \\
\hline Gia sư & 64 & 10.8 \\
\hline $\begin{array}{c}\text { Làm việc phù hợp với chuyên } \\
\text { ngành được đào tạo }\end{array}$ & 112 & 18.9 \\
\hline Bán hàng online & 136 & 22.9 \\
\hline $\begin{array}{c}\text { Phục vụ nhà hàng và khu vui chơi } \\
\text { Tiềp thị sản phấm cho các doanh } \\
\text { nghiệp và phát tờ rơi }\end{array}$ & 125 & 12.0 \\
\hline Lao động thù công đơn thuần & 84.1 \\
\hline Khác & 1 & 14.2 \\
\hline
\end{tabular}

Nhân xét: sinh viên làm thêm nhiêu công việc khác nhau. Làm việc phù hợp với chuyên ngành được đào tạo (18.9\%); Gia sư: $10.8 \%$; Chủ yếu là tiếp thị sản phẩm cho các doanh nghiệp và phát tờ rơi (21.1\%); Bán hàng online (22.9\%)

Bảng 6: Số giờ làm thêm trong ngày

\begin{tabular}{|c|c|c|}
\hline $\mathbf{n}=\mathbf{5 9 3}$ & $\mathbf{S L}$ & $\mathbf{( \% )}$ \\
\hline Dưới 4 giờ & 299 & 50.4 \\
\hline Từ 4 đến 6 giờ & 211 & 35.6 \\
\hline Từ 6 -8 giờ & 60 & 10.1 \\
\hline Từ 8-12 giờ & 23 & 3.9 \\
\hline Khác & 0 & 0 \\
\hline
\end{tabular}

Nhân xét: $50.4 \%$ sinh viên làm thêm dưới 4 giờ/ngày; $10.1 \%$ sinh viên làm thêm từ 6 đến 8 giờ/ngày. Thậm chí có $3.9 \%$ sinh viên làm thêm từ 8-12h/ngày.

Bảng 7: So sánh kêt quả học tập năm hoc 2018-2019 của 02 nhóm đôi tượng: Sinh viên có đỉ làm thêm và Sinh viên không đi làm thêm

\begin{tabular}{|c|c|c|c|c|}
\hline \multirow{2}{*}{ Loại } & \multicolumn{2}{|c|}{$\begin{array}{c}\text { Sinh viên có đi } \\
\text { làm thêm }\end{array}$} & \multicolumn{2}{c|}{$\begin{array}{c}\text { Sinh viên không } \\
\text { đí làm thêm }\end{array}$} \\
\cline { 2 - 5 } & $\mathbf{n = 5 9 3}$ & $\mathbf{\%}$ & $\mathbf{n = 8 4 0}$ & $\mathbf{\%}$ \\
\hline Loại Giỏi & 27 & 4.6 & 79 & 9.4 \\
\hline Loại Khá & 301 & 50.7 & 482 & 57.4 \\
\hline Laại TB & 259 & 43.7 & 275 & 32.7 \\
\hline Khác & 6 & 1.0 & 4 & 0.5 \\
\hline
\end{tabular}

Nhận xét: năm học 2018-2019, sinh viên không đi làm thêm có kết quả học tập đat loai khá giỏi là $66.8 \%$ trong đó tỷ lệ giỏi: $9,4 \%$ ) cao hơn tỷ lệ này của nhóm sinh viên có đi làm thêm (55.3\% trong đó tỷ lê giỏi: $4.6 \%$ ).

Bảng 8: Ánh hưởng tới học tập từ đỉ làm thêm

\begin{tabular}{|c|c|c|}
\hline (n = 593) & SL & $\mathbf{( \% )}$ \\
\hline $\begin{array}{c}\text { Phải nghî học trên lớp khi lịch } \\
\text { làm thêm trùng với lịch học }\end{array}$ & 147 & 24.7 \\
\hline Kết quả học tập giảm sút & 323 & 54,5 \\
\hline $\begin{array}{c}\text { Đam mê thu nhập từ làm thêm } \\
\text { dẫn tới sao lẫng học tập }\end{array}$ & 144 & 24.3 \\
\hline
\end{tabular}

Nhận xét: 24.7 sinh viên đi làm thêm cho rằng có thể phải nghỉ học trên lớp khi đi làm thêm; $54.5 \%$ sinh viên đi làm thêm cho rằng: kết quả học tập giảm sút khi đi làm thêm. 
Bảng 9: Mong muốn nhận được sự tư vân, hồ trợ của sinh viên đi làm thềm

\begin{tabular}{|c|c|c|}
\hline & SL & $(\%)$ \\
\hline $\begin{array}{l}\text { Có mong muốn nhận được sự } \\
\text { tư vấn, hỗ trợ }(n=593)\end{array}$ & 559 & 94.3 \\
\hline \multicolumn{3}{|c|}{ Nội dung mong muốn được tư vấn, hô trợ (559) } \\
\hline $\begin{array}{c}\text { Tư vấn, giới thiệu việc làm phù } \\
\text { hợp với điều kiện sống và học } \\
\text { tập của sinh viên }\end{array}$ & 338 & 60.4 \\
\hline $\begin{array}{c}\text { Tư vấn, giới thiệu việc làm phù ù } \\
\text { hợp với ngành đào tạo đang } \\
\text { theo học }\end{array}$ & 287 & 51.3 \\
\hline $\begin{array}{c}\text { Tư vấn cung cấp kỹ năng, kiến } \\
\text { thức liên quan đến đảm bảo } \\
\text { quyền lợi khi đi làm thêm }\end{array}$ & 205 & 36.7 \\
\hline Khác & 0 & 0 \\
\hline
\end{tabular}

Nhân xét: $94.3 \%$ sinh viên đi làm thêm có mong muốn nhân được sư tư vấn, hỗ trơ về giới thiệu việc làm và cung cấp kỹ năng, kiến thức liên quan đến đảm bảo quyên lợi khi đi làm thêm

\section{BÀN LUÂN}

1. Thức trang đi làm thêm của sinh viên Trường Đại học Kỹ thuật $Y$ tế Hải Dương năm 2019

- Tỷ lệ sinh viên đi làm thêm. Năm 2019, tỷ lệ sinh viên trường $Đ H$ Kỹ thuật y tế Hải dương đi làm thêm/tổng số đối tượng nghiên cứu là $41.4 \%$ (bảng 2). Tỷ lệ này thấp hơn nghiên cứu của Vương Quốc Duy tại Trường Đại học Cần Thơ (2015), tỷ lệ sinh viên đi làm thêm là $50,3 \%$ [1].

- Lý do sinh viên đi làm thêm. Có nhiều lý do khiến sinh viên đi làm thêm. Trong đó lý do chủ yễu là: muốn có thu nhập: $42.2 \%$ (Bảng 3 ). Kết quả này có điểm tương đồng so với nghiên cứu của Nguyễn Xuân Long [2] và Trần Thu Hương[3]. Theo Nguyễn Xuân Long: 31,3\% sinh viên đi làm thêm với lý do chủ yếu là muốn tăng thu nhập; theo Trần Thu Hương: 39,74\% sinh viên đi làm thêm với lý do chủ yếu là muốn tăng thu nhập. tương đồng với nghiêm cứu của HSBC Group: hâuu hết sinh viên đi làm thêm là do họ cần kiếm thêm tiền (53\%)[5].

Lý do tiếp theo là muốn tự khẳng định bản thân: 42.2\%; Kết quả này tương đồng so với nghiên cứu của Trần Thu Hương [3]: 41,72\% sinh viên đi làm thêm do muốn tự khẳng định bản thân.

- Tiêu chí được sinh viên quan tâm khi lựa chọn công việc làm thêm và tính chất công việc làm thêm của sinh viên

Tiêu chí được sinh viên quan tâm nhất khi lựa chọn công việc làm thêm là: Thời gian làm việc khồng trùng với lịch học tại trường: 69.8\%;
Công việc làm thêm liên quan đến chuyên ngành đang theo học: $42.5 \%$; Thu nhập cao: $35.2 \%$; Có cơ hội trải nghiệm, tích luỹ kiến thức sống, kiến thức thực tế và có cơ hội phát triển kỹ năng giao tiếp: 26.3-36.1\% (Bảng 4).

Sinh viên làm thêm nhiều công việc khác nhau. Chủ yếu là tiếp thị sản phẩm cho các doanh nghiệp và phát tờ rơi (21.1\%); Bán hàng online $(22.9 \%)$; Làm việc phù hợp với chuyên ngành được đào tạo (18.9\%); gia sư $(10.8 \%) ;$ Ngoài ra làm một số công việc khác như: phục vụ nhà hàng ăn uống và khu vui chơi giải trí,... 14.2\% sinh viên đi làm thêm làm công việc lao động thủ công đơn thuần. (Bảng 5).

Như vậy ngoài $18.9 \%$ sinh viên làm việc phù hợp với chuyên ngành được đào tạo và $10.8 \%$ sinh viên làm gia sư còn lại; $70.3 \%$ sinh viên đi làm thêm làm các công việc trái với ngành nghề được đào tạo, thậm chí làm công việc lao động thủ công đơn thuần. Kết quả nghiên cứu tương đồng với kết quả nghiên cứu của Vương Quốc Duy [1] về công việc làm thêm của sinh viên: phần lớn sinh viên làm nhân viên phục vụ $(40,2 \%)$, làm gia sư chiếm $15 \%$, còn lại là các công việc đa dạng khác như tự kinh doanh, làm CTV nghiên cứu thị trường, phát tờ rơi, v.v.

Điều này tương đồng với nhận định của Đinh Thị Mỹ Lệ khi nghiên cứu sự ảnh hưởng của đi làm thêm đối với sinh viên đại học Duy Tân [4]: Những công việc làm thêm thường trái với ngành nghề được đào tao do vây chưa vận dụng hoă̆c là không vận dụng được hết các kiến thức đã học vào thực tế; đồng thời những công việc làm thêm thường mất khá nhiều thời gian, sức khỏe làm ảnh hưởng không nhỏ đến kết quả học tập của người học

- Thời gian làm thêm. 50.4\% sinh viên làm thêm dưới 4 giờ/ngày; $35.6 \%$ sinh viên làm thêm từ 4 đến 6 giờ/ngày; $10.1 \%$ sinh viên làm thêm từ 6 đến 8 giờ/ngày. Thâm chí có $3.9 \%$ sinh viên làm thêm từ 8-12h/ngày (Bảng 6). Đối với sinh viên ngành $y$, đòi hỏi cần đâu tư thời gian học tập và tự học, nếu sinh viên đi làm thêm mất nhiều thời gian trong ngày cho việc làm thêm, điêu đó sẽ ảnh hưởng tới kế hoạch học tập và tự học. Mặt khác quá trình làm thêm sẽ ảnh hưởng tới sức khỏe, điêuu này sẽ ảnh hưởng tới hoc tập.

- So sánh kết quả học tập năm học 2018-2019 của viên đỉ làm thêm và sinh viên không đi làm thêm. Sinh viên không đi làm thêm có kết quả học tập năm học 20182019 đạt loại giỏi và khá là $9,4 \%$ và $57.4 \%$; tỷ lệ này của sinh viên có đi làm thêm là $4.6 \%$ và 
$50.7 \%$. Tỷ lệ sinh viên đi làm thêm có kết quả học tập đạt loại trung bình là $43.7 \%$, tỷ lệ này của nhóm sinh viên không đi làm thêm là $32.7 \%$ (Bảng 7). Như vậy sinh viên không đi làm thêm có kết quả học tập cao hơn so với nhóm sinh viên đi làm thêm.

- Ảnh hưởng tới học tập từ đỉ làm thêm. $24.7 \%$ sinh viên cho rằng một trong những nguy cơ từ làm thêm là phải nghỉ học trên lớp khi lịch làm thêm trùng với lịch học; $54.5 \%$ cho rằng làm thêm có thể khiến kết quả học tập giảm sút; $40.7 \%$ cho rằng dễ bị cám dỗ, sa ngã. (Bảng 8). Đam mê đi làm do làm thêm mang lại thu nhập dẫn tới sao nhãng việc học tập (24.3\%).

- Mong muốn của sinh viên về việc nhận được tư vấn, hỗ trợ khi đi làm thêm. $94.3 \%$ sinh viên đi làm thêm mong muốn nhận được sự tư vấn, hố trợ khi đi làm thêm. Nội dung mong muốn được tư vấn, hỗ trợ chủ yếu là giới thiệu việc làm phù hợp với điêu kiện sống và học tập: $60.4 \%$; Tư vấn, giới thiệu việc làm phù hợp với ngành đào tạo đang theo học: $51.3 \%$; Tư vấn cung cấp kỹ năng, kiến thức liên quan đến đảm bảo quyền lợi khi đi làm thêm: $36.7 \%$ (Bảng 9).

2. Đề xuất giải pháp tăng cường quản lý, hỗ trợ người học trong tìm kiếm việc làm thêm và đỉ làm thêm

- Đối với nhà trường: Bổ sung quy chế, quy định về quản lý sinh viên đi làm thêm, quy định rõ nội dung sinh viên cần phải báo cáo cố vấn học tập và nhà trường về việc đi làm thêm trong thời gian học tâpp tại trường; Quy định về tính chất công việc làm thêm, những công việc được phép làm và những công việc không được phép làm; thời gian được phép làm thêm/ tuần; điêu kiện về kết quả học tập để được phép làm thêm... Đồng thời bổ sung Quy chế Công tác quản lý sinh viên và quy chế đánh giá điểm rèn luyện, khung trừ điểm rèn luyện, các hình thức xử lý kỷ luật khi vi phạm các quy định về làm thêm.

- Đối với các phòng chức năng, khoa/bộ môn: Thực hiện tốt vai trò phối hợp trong quản lý, giám sát sinh viên đi làm thêm

Phòng Công tác quản lý sinh viên thực hiên chức năng hỗ trợ, tư vấn giới thiệu việc làm cho sinh viên đồng thời tham mưu cho Hiệu trưởng trong việc xây dựng và ban hành quy chế quy định, quản lý sinh viên đi làm thêm trong quá trình học tập tại trường đồng thời có cơ chế quản lý, giám sát việc đi làm thêm của sinh viên trên cở sở quy chế, quy định được ban hành.

- Cố vấn học tập. Cố vấn học tập cần nắm bắt thông tin vể tình hình đi làm thểm của sinh viên trong lớp do mình quản lý. Sinh viên muốn đi làm thêm phải báo cáo và được sự đồng ý của cố vấn học tập. qua đó để cố vấn học tập biết được sinh viên đó đang làm việc gì? Làm ở đâu? Thời gian cho làm thêm là bao nhiêu và lực học, kết quả học tập của sinh viên như thế nào? Việc đi làm thêm có làm giảm sút kết quả học tập của sinh viên đó hay không? đề xuất kịp thời với nhà trường các giải pháp phù hợp trong việc hỗ trợ sinh viên.

- Đối với các tổ chức đoàn thể:

- Đoàn Thanh niên, Hội sinh viên tổ chức các hoạt động hỗ trợ, cung cấp thông tin tư vấn, tư vấn giới thiệu việc làm cho sinh viên;

- Thực hiện công tác tuyên truyền phổ biến pháp luật nhằm chia sẻ kinh nghiệm, thông tin tìm kiếm việc làm đồng thời nâng cao kiến thức pháp luật, kỹ năng xã hội cho người học có các giải pháp để phòng tránh rủi ro, nguy cơ và tự bảo vệ bản thân khi đi làm thêm.

\section{KẾT LUÂN}

- Tỷ lệ sinh viên đi làm thêm: 41.4\%;

- Lý do chủ yếu của việc đi làm thêm là: muốn có thu nhập: $42.2 \%$; muốn tự khẳng định bản thân: $42.2 \%$; Trang trải cho nhu cầu học tập, sinh hoạt của bản thân; 9,1\%; Tận dụng thời gian rảnh rỗi; $6.1 \%$; Rèn luyện kỹ năng làm việc; tích lũy kinh nghiệm cho nghề nghiệp hoặc tìm cơ hội việc làm sau khi tốt nghiệp: 1\%-3,9\%.

- Tính chất công việc làm thểm: Làm việc phù hợp với chuyên ngành được đào tạo: $18.9 \%$; gia sư: $10.8 \%$; tiếp thị sản phẩm cho các doanh nghiệp và phát tờ rơi: $21.1 \%$; Bán hàng online: $22.9 \%$; lao động thủ công đơn thuần: $14.2 \%$; phục vụ nhà hàng ăn uống và khu vui chơi giải trí: $12 \%$;

- Thời gian làm thêm: dưới 4giờ/ngày: $50.4 \%$; 4 đến 6 giờ/ngày: $35.6 \%$; $6-8$ giơ/ngày $10.1 \% ; 8-12 \mathrm{~h} /$ ngày: $3.9 \%$

- $54.5 \%$ sinh viên đi làm thêm cho rằng việc đi làm thêm khiến ảnh hưởng tới quá trình học tập và khiến kết quả học tập giảm sút.

- 94.3\% sinh viên đi làm thêm mong muốn nhận được sự tư vấn, hỗ trợ khi đi làm thêm; bao gồm: được giới thiệu việc làm phù hợp với điều kiện sống và học tập: 60.4\%; Tư vấn, giới thiệu việc làm phù hợp với ngành đào tạo đang theo học: $51.3 \%$; Tư vẫn cung cấp kỹ năng, kiến thức liển quan đến đảm bảo quyền lợi khi đi làm thêm: $36.7 \%$

\section{TÀI LIỆU THAM KHẢO}

1. Vưởng Quốc Duy và cộng sự: "Xác định các nhân tố ảnh hưởng đến quyết định đi làm thêm của sinh viên Đại học Cân Thơ, 2015" Tạp chí 
khoa học Đại học Cần Tho. 40 (2015): 115-113.

2. Nguyễn Xuân Long (2009): "Nhu cầu làm thêm của sinh viên trường Đại học Ngoại ngữ - Đại học quốc gia Hà Nô̂i: Thực trạng và giải pháp". Tạp chí Tâm lý hoc. số 9 (126), 9-2009.

3. Trân Thu Hương. Nữ sinh với việc làm thêm.
Khoa tâm lý học, Trường Đại học KHXH và nhân văn - ĐHOG Hà Nội

4. Đinh Thị Mỹ Lệ. Việc làm thêm có ảnh hưởng như thế nào đối với sinh viên duy tân.

5. HSBC Group. Education Market Reports 2018. Trends, Analysis \& Statistics.

\title{
HIÊUU QUẢ BỔ SUNG SŨ̃A BộT HANIE KID LÊN TÌNH TRANG DINH DƯỠNG, SỨC KHỎE VÀ KHẢ NĂNG CHẤP NHÂ̂N SẢN PHẨM CỦA HỌC SINH LỚP MộT
}

\author{
Phạm Quốc Hùng ${ }^{1}$, Trần Đình Thoan ${ }^{2}$, Nguyễn Văn ${ }^{3}$, Trần Thúy Nga
}

\section{TÓM TẮT}

Nghiên cứu có đối chứng, ngẫu nhiên cụm nhằm đánh giá hiệu quả bổ sung "Sản phẩm dinh dưỡng dành cho trè từ 2-10 tuổi Hanie Kid 2+" dạng lên tình trạng dinh dưỡng, sức khỏe và khả năng chấp nhân sản phẩm đối với học sinh lớp một (6-7 tuổi). Nghiển cứu đước hoàn thành tai Thái Bình vào tháng 3/2021 với 55 trẻ nhóm can thiệp bổ sung Sữa bột Hanie Kid 2 lần/ngày trong 2 tháng và 55 trẻ nhóm chứng chế độ ăn thông thường. Kết quả nghiên cứu cho thấy bổ sung Sữa bột Hanie Kid đã có tác động tích cực: cân nặng trung bình tăng $0,5 \mathrm{~kg}(0,86 \pm 0,29 \mathrm{~kg}$ so với $0,36 \pm 0,17 \mathrm{~kg} ; \mathrm{p}<0,01)$; chiêuu cao trung bình tăng $0,29 \mathrm{~cm}(0,88 \pm 0,29 \mathrm{~cm}$ so với $0,59 \pm 0,17 \mathrm{~cm} ; \mathrm{p}<0,05)$; SDD thể nhe cân giảm 10,9\%; nguy cơ SDD nhe cân giảm $14,5 \%$ có ý nghĩa thống kê $(p<0,05)$. Có $x u$ hướng cải thiện tình trạng nhiếm khuẩn hô hấp, tiêu chảy, táo bón, biếng ăn, khó ngủ nhưng số lượng nhỏ, không có ý nghĩa thống kê ( $p>0,05)$.

Từ khóa: đa vi chất, sữa bổ sung, trẻ tiểu học, chiều cao, cân nặng

\section{SUMMARY}

EFFECTS OF HANIE KID FORMULA SUPPLEMENT ON NUTRITION STATUS, HEALTH, AND PRODUCT ACCEPTABILITY OF GRADE ONE STUDENTS

A cluster randomized and controlled study was conducted to evaluate the supplemental effects of "Hanie Kid 2+ formula milk nutrition product" on nutritional status, health and product acceptability for first graders (6-7 years old). The study was completed in Thai Binh in March 2021 with 55 infants supplemented with Hanie Kid Formula Milk 2 times/day for 2 months and 55 control children using

\footnotetext{
${ }^{1}$ Trường Đại học Y Hà Nội

2Trường Đại hoc Y Dước Thái Bình

${ }^{3}$ Trường Cao đẳng Y tế Hà Tình

${ }^{4}$ Viện Dinh dưỡng Quốc gia

Chịu trách nhiệm chính: Phạm Quốc Hùng

Email: phamquochung@hmu.edu.vn

Ngày nhận bài: 13.4.2021

Ngày phản biện khoa học: 25.5.2021

Ngày duyệt bài: 14.6.2021
}

regular diet. Research results showed that Hanie Kid Formula Milk supplementation had positive effects: average weight increased by $0.5 \mathrm{~kg}(0.86 \pm 0.29 \mathrm{~kg}$ vs. $0.36 \pm 0.17 \mathrm{~kg} ; \mathrm{p}<0.01)$; average height increased by $0.29 \mathrm{~cm}(0.88 \pm 0.29 \mathrm{~cm}$ vs. $0.59 \pm 0.17 \mathrm{~cm} ; \mathrm{p}$ $<0.05)$; underweight decreased $10.9 \%$; The risk of underweight malnutrition decreased by $14.5 \%$, with statistically significant $(p<0.05)$. Tendly improve respiratory infections, diarrhea, constipation, anorexia, and difficulty sleeping but having small quantity and not statistically significant $(p>0.05)$.

Keywords: micronutrients, formula milk, primary school student, height, weight

\section{I. ĐẠT VẤN ĐÊ}

Tình trạng suy dinh dưỡng (SDD) nhẹ cân, thấp còi của trẻ em, đặc biệt là vùng nông thôn Việt Nam còn là vấn đề sức khỏe quốc gia ảnh hưởng đến tầm vóc, chiều cao, trí tuê và sức lao động của người Việt và được ngành y tế và Chính phủ đặc biệt quan tâm[1]. Một trong những biện pháp hữu hiệu là sử dụng sữa được bổ sung vi chất dinh dưỡng (VCDD) [2],[3]. Thành phần, hàm lượng, khẩu phần sữa bổ sung cho trẻ em còn là vấn đề tranh luận. "Sản phẩm dinh dưỡng dành cho trẻ từ 2-10 tuổi Hanie Kid 2+" dạng bột (gọi là Sữa bột Hanie Kid) của NutriCare cân đối năng lượng, chất béo, protein, DHA, FOS/Inulin, HMO (2'-FL), Lysin và bổ sung 28 loại vitamin, khoáng chất theo hướng dẫn của WHO [4] hướng tới đối tượng đích là trẻ em lứa tuổi 2-10 tuổi. Nghiên cứu này nhằm đánh giá hiệu quả của Sữa bột Hanie Kid đối với tình trạng dinh dưỡng, sức khỏe và khả năng chấp nhận sản phẩm ở trẻ lớp một (6-7 tuổi).

\section{II. ĐỐI TƯƠNGG VÀ PHƯƠNG PHÁP NGHIÊN CỨU \\ Đối tượng nghiên cứu: trẻ lớp một ở 02} Trường Tiểu học \& Trung học cơ sở thuộc huyện Kiến Xương, tỉnh Thái Bình đáp ứng tiểu chuẩn chấp nhân và loại trừ nghiên cứu. Tiêu chuẩn lựa chọn: Trẻ học lớp một; đang theo học tại trường; không mắc các dị tật bẩm sinh, khuyết 